\title{
EVALUATION OF RESTORATION PROJECTS FOR THRONE VILLAGES' PALACES AND FORTRESSES
}

\author{
HAYA S. NASEREDDIN, ILHAM S. NASEREDDIN \& GHASSAN J. DWEIK \\ Department of Civil Engineering and Architecture, Palestine Polytechnic University, Palestine
}

\begin{abstract}
Throne villages, Palestinian villages known for the political or military power of their local leaders, gained the name from having their own separate administrations. Located strategically in the central mountains of Palestine, such as the mountains of Jerusalem, Hebron and Nablus, Throne villages were well known for their defensive architecture and fortresses, especially during the latter half of Ottoman rule in the 18th and 19th centuries. The purpose of this research is to design a strategic work plan to revive and reuse these architectural sites, in order to achieve a plan for the sites economic and cultural sustainability. In this paper, we analysed the defensive reasoning, architectural characteristics, functions and internal spaces of the Throne villages' palaces and fortresses. We discuss two case studies of the Throne villages architecture: the Barqawi Fortress in Shoufa village, and Al-Jayyousi Palace in Kour Village, Tulkarm. We present an evaluating study of the restoration projects for both architectural sites, the effects on each site, followed by an analytical study of the causes for its current conditions. Our research methodology depended on the historical documentation, on reviewing the previous studies and historical background, investigation, site visits, and personal interviews with representatives from the Throne village families. This paper concludes with proposed design strategies for the strategic work plan, to be able to revive and reuse these architectural sites, and suggests how it could be applied. Keywords: defensive architecture, historic architecture, historic village, Ottoman rule, Ottoman architecture, Palestine, restoration, sustainability, throne village, urban planning.
\end{abstract}

\section{INTRODUCTION}

Historically, many places in Palestine were named after the locations topography, a common type of vegetation, a certain religious symbolism, or for the common function of each village: for example, military or defensive villages. Such villages mainly go back to periods of either Roman or Ottoman rule in Palestine. These villages have much in common, such as the language, culture and religion. Some of these villages where called Throne villages [1].

During the 18th and 19th centuries, the middle mountains of Palestine that are known today as the West Bank, were divided into 24 administrative counties, each one known as a Mashyakha (plural: Mashayekh), were strategically located within Palestine mainly in the central mountains of Nablus, Hebron and Jerusalem (Fig. 1). Jammain, Shoufa, Kour and Arraba are examples of Throne villages in Nablus; while Dura is in Hebron; and Abu-Dees is in Jerusalem [1].

The counties (Mashayekh) differed in size and the number of villages, for example, Mashyakha Jammain in Nablus included 40 villages. In Ramallah, Bani-Hareth Mashyakha included 11 villages. The counties were ruled by local leaders whom were from noble and rich families. The villages where the governors lived with their families were called Throne villages: each was considered the administrative and political capital of its county [2]. Throne village governors were called "Sheikh". These local rulers were from wealthy families in charge of tax collection for the Ottomans; which had gained them great influence and wealth. This was reflected on their residences architecture; for example, their palaces were built in rural districts, each with its unique architectural details, areas, functions, mosaics and art walls. Moreover, their defensive features were notable [3]. 


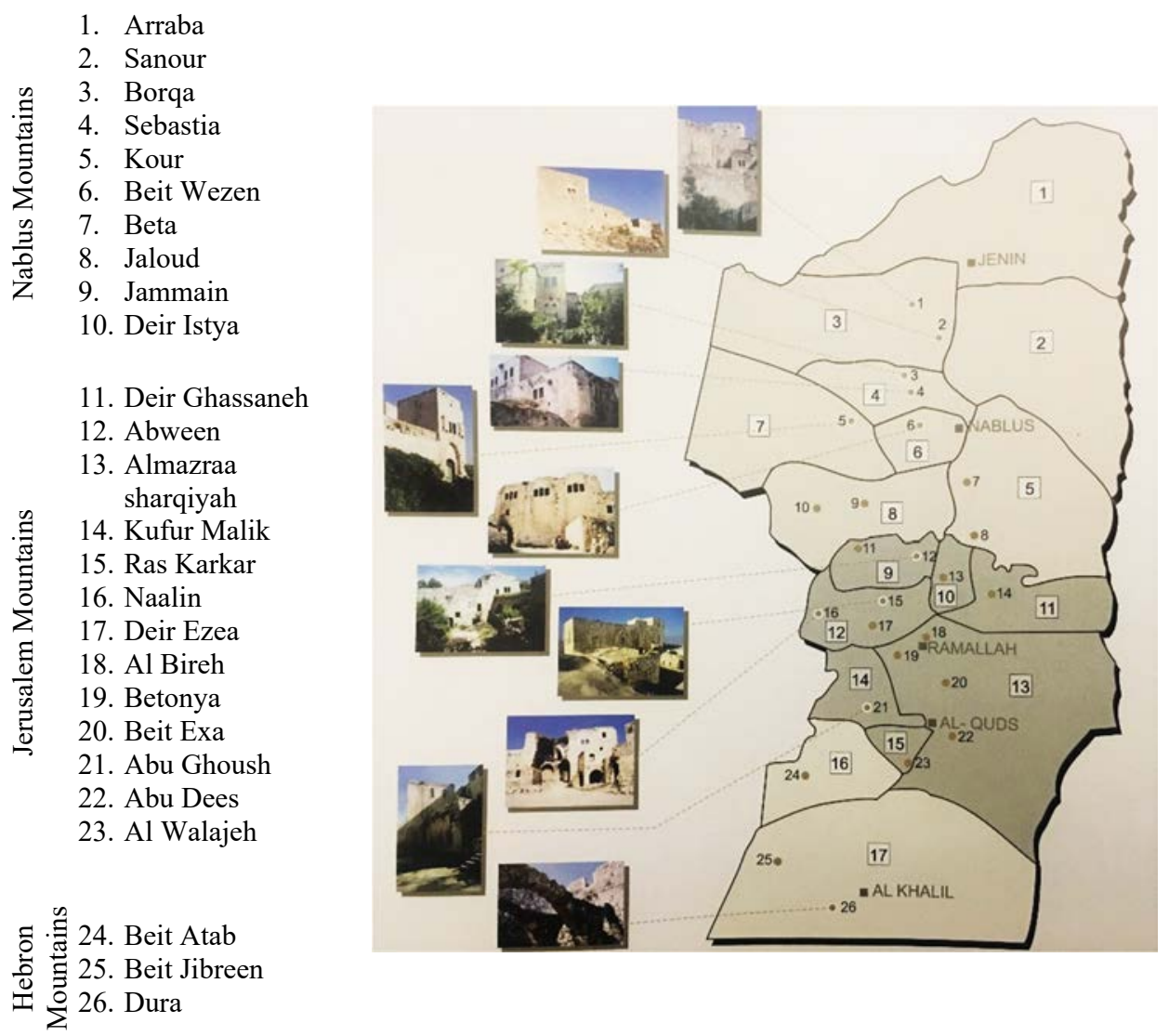

Figure 1: Throne villages in the central Palestinian mountains [3].

This paper introduces a brief historical description to the factors influencing Throne village architecture, as well as highlighting the main internal functions of these village residences. Our paper illustrates two case studies near Tulkarm, which are the villages of Shoufa and Kour. These two villages, among others, were selected to analyze two of the main Throne village building types, the palaces residences and the defensive castles. This study aims to evaluate the building restoration projects achieved. We give recommendations for developing these restoration projects of such great architectural heritage.

\section{THRONE VILLAGE ARCHITECTURE}

The architecture of the Throne villages emerged in response to the main factors that played a key role in the residents lifestyle and in their building typology. These factors can be summarised as follows [3], [4]:

- The economic factor and the massive amount of money collected by the governors or feudal leaders: the source was mainly tax collection. Their economic power was reflected in the architectural form and in the buildings scale. Construction included massive buildings with higher walls in castles and palaces. 
- The military factor, or the governing families need for safety and security: this period witnessed the construction of castles and palaces to protect the leaders from repellents, mainly due to the tax collection.

- The social factor and the governors political positions, mainly reflected in the architecture of their residents, where palaces and castles were recognized as ruling and administrative buildings and destinations (also named as "The Saraya").

- The female residents presence and influence as a part of society, and their contribution to the governor's responsibilities.

The above-mentioned factors highly affected the internal functions of the palaces and castles in Throne villages. Furthermore, the functions and interior layout were related to the political, social and economic roles played by their owners, back in the 18-19th centuries [2].

Privacy had always been one of the fundamental requirements for residential buildings in the Islamic culture; therefore, palaces spaces within Throne villages were divided either to have high-privacy spaces or as semi-public spaces. The first were used as residential spaces for the governor's family; while the second acted as the village headquarters for the county's administrative, military and public affairs. The palaces also played the role of the Saraya (such an example was Abdullah Al-Jayyousi palace in Kour, Tulkarm) [5].

The internal facilities of a palace could also be classified, in terms of the spaces use, into three main parts: The first are general administrative facilities, such as "The Diwan", which played an important role in political and social life, were where the Sheikh met his guests, guards and even prisoners. All of these facilities were on the palace's ground floor, except for the sheikh's attic, which was found in the upper floors with another dependent main entrance. The second main part was facilities with service functions, located on the ground floor or the basement, like the corridors, stables, storage and water wells. The third main part is the residences facilities, which included the family living room on the ground floor and bedrooms with arcades which open towards the internal courtyard on the upper floors [2].

The architecture within Throne villages was slightly affected by each village's geographical location; however, mutual architectural elements and characteristics were found both in form and function in palaces and castles, summarized as follows [2], [6]:

1. Location: The palaces of Throne villages were very similar to castles in defensive form, also with a centric location with respect to the rural agricultural houses, emphasizing the rulers strength and control. The location of the governor's palace was either centric, like Deir Ghassaneh and Ras Karkar in Nablus, or on the outer borders of the village, for example Sanour castle in Sanour, Nablus.

2. Walls: Protection and defense were important factors in Throne villages; however, the walls were built to surround only the governor's palace, not the whole village. All village palaces and castles were characterized by having high defensive walls, and these walls mostly formed the palaces outer façades and the walls of internal courtyards. In addition to the main defensive function of the walls, an ultimate social need was to provide privacy for the governor's family, especially women (Fig. 2(a)).

3. Courtyards: The internal courtyard, considered the main architectural feature in these palaces; was found in all county palaces, and the rooms were distributed around the courtyard, in two to three floors (rarely in four floors). The palaces most vital space, they were where women worked, kids played and social occasions like weddings and feasts occurred. The courtyard was surrounded with arcades as an extension to the court and as an entrance to the surrounding rooms (Fig. 2(b)). 
4. Vaults and domes: cross vaults were a common construction solution for palaces and castles, as shown in Fig. 3. On the other hand, domes were used in religious buildings like mosques; and in some of the palaces attics, as a decorative element on an octagon drum.

5. Openings: All openings in the palaces and castles in throne villages were small openings, except for the main entrances. Solid façades were one of the main architectural features. Openings were mostly oriented toward the courtyard, especially on the ground floor. The size of the windows gradually increased toward higher floors; for further adoption of the concepts of defense and privacy. The most common windows were the double rectangular windows, as shown in Fig. 4, in a residential neighbourhood in Anabta, Nablus.

6. Decorative elements: the decorative elements varied from reliefs of geometric shapes, plans and floral motifs, carved wood decorations, coloured ceramics, decorations and colouring of internal domes, as shown in Figs 5-7. Also, coloured wooden ceiling, Mashrabiya and the pottery openings on the roofs, which acted as decorative elements and provided privacy.

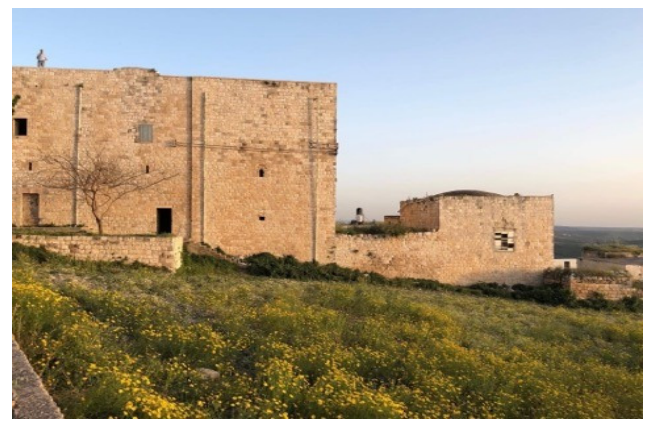

(a)

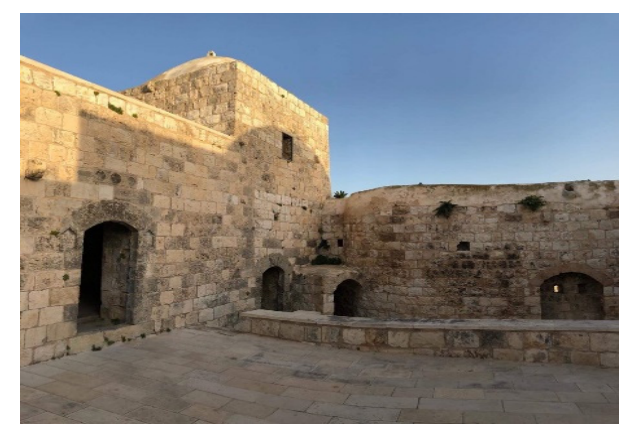

(b)

Figure 2: Kour. (a) Walls of Sheikh castle; and (b) Courtyard of Sheikh castle, Kour. (Source: Researcher, 2019.)

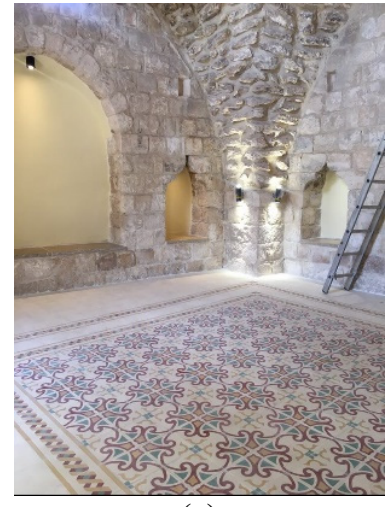

(a)

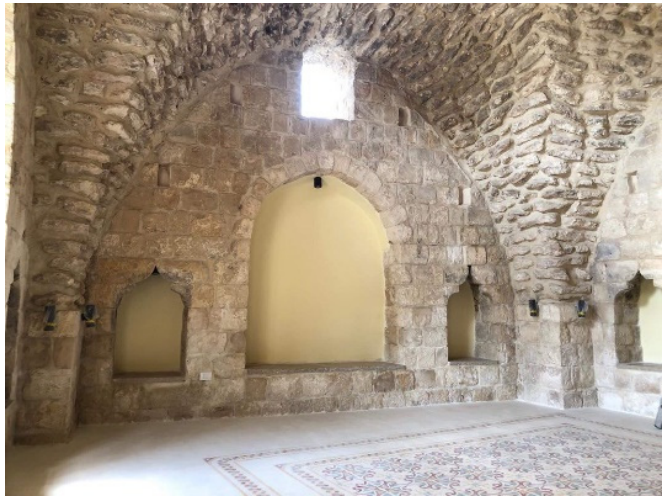

(b)

Figure 3: Cross vault in one of the palaces in Anabta, Nablus. (Source: Researcher, 2019.) 


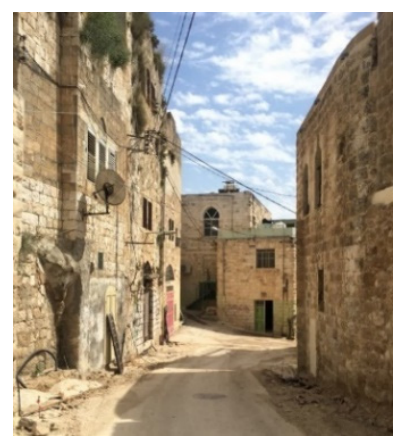

(a)

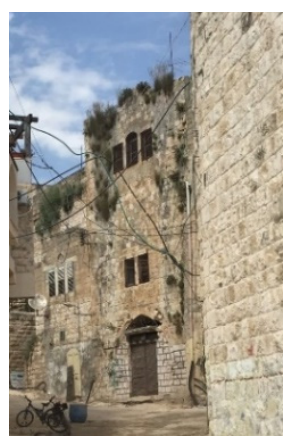

(b)

Figure 4: The double window in Anabta. (Source: Researcher, 2019.)

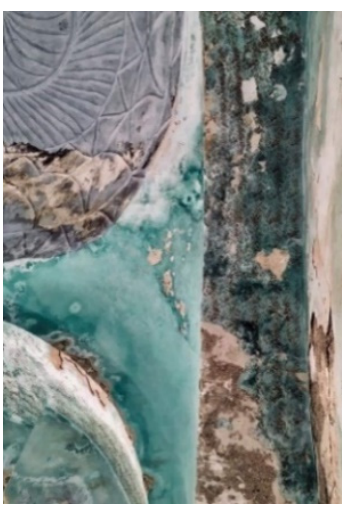

(a)

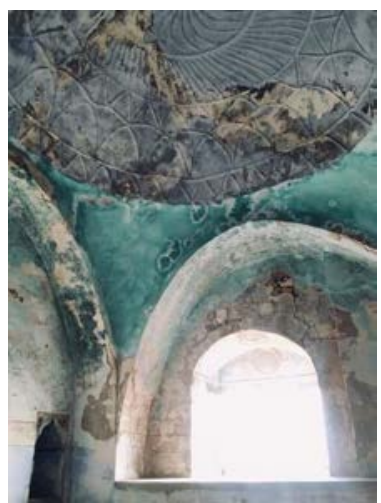

(b)

Figure 5: Painted coloured ceilings in a room in Al Hakem castle, Kour. (Source: Researcher, 2019.)

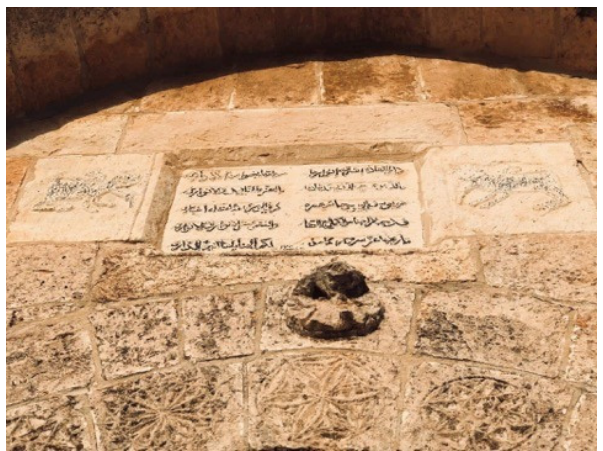

Figure 6: Stone relief at the entrance of Al Barqawi castle, Shoufa, Tulkarm.

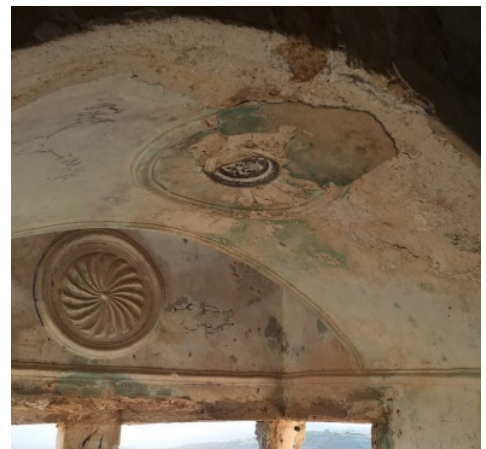

Figure 7: Colored ceramic above windows in Al Hakem castle, Kour. (Source: Researcher, 2019.) 


\section{CHALLENGING PRESENT OF THRONE VILLAGES}

The architecture of Throne villages is nowadays facing major challenges. The two most important threats are the weather and human behaviour. This paper focuses on the latter cause of damage to this inherited architectural treasure. The lack of awareness of the importance of these palaces and castles as a cultural heritage; moreover, the absence of accountability to the causes of damage from the local authorities. The forms of human-made damage are summarised as follows [7].

\subsection{Abandoned and unoccupied buildings}

Changing social needs and the lack of jobs in these villages has led their original residents to look for other opportunities outside their hometowns, setting new destinations leaning toward larger cities, like Ramallah and Nablus. The impact of abandoning the palaces and castles of throne villages can be referred to in two cases; either the buildings are left unoccupied or they are inhabited by residents other than their original owners [8].

The first, leaving the building uninhabited or unused for a long time with no periodic maintenance, results in problems such as roof leakage, as well as issues with garbage collection. The effect also extends to pose a real social threat among the youth, for example, problems such as drugs. Al Hakem Palace in Kour is an example of this case, which restored Kour Palaces that were left unused since then, as shown in Fig. 8.

The second refers to situations where these palaces or castles were used as rental properties, which has led to a serious deterioration of the old buildings, due to the exploitation by mostly low-income residents other than their original owners [8]. The lack of responsibility and appreciation may cause the building serious damage; most of the historic palaces of Kour village were damaged, due to this reason. Changing the interior functions of the buildings spaces, adding or demolishing parts of the original building, changes its original nature, form, function and more importantly, its identity. Al Jayyousi palace in Kour has suffered from such interventions, which negatively affected the functioning of the courtyard, like the addition of an inconsistent external extension, built with concrete block, the dangling electrical wires and water sanitation pipes and closing of the arcades and some windows, as shown in Fig. 9.

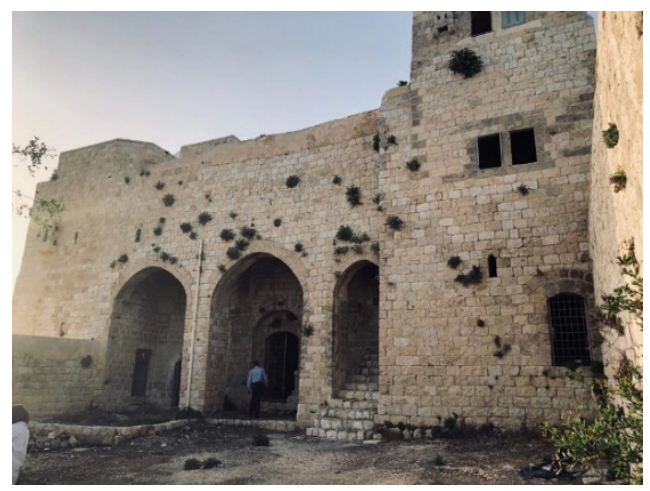

Figure 8: Al Hakem palace main entrance, Kour, Tulkarm.

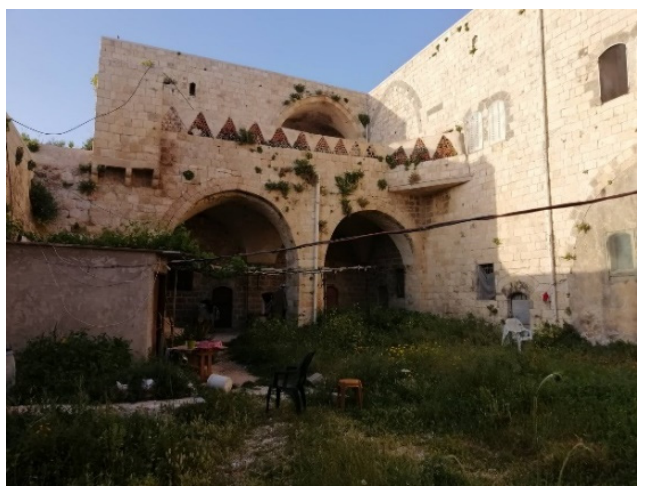

Figure 9: Interventions in Al Jayyousi palace, Kour, Tulkarm. (Source: Researcher, 2019.) 


\subsection{Random urban expansion}

Uncontrolled and unplanned urban expansion is at present one of the main challenges to be highlighted, as both vertical or horizontal urban expansion require complete or partial demolishing of some old buildings; or on the other hand, the addition of inhomogeneous spaces to the original building. As for Kour; the buildings new expansion was mostly by the addition of plastered concrete block (Fig. 10). Personal interviews indicate high rates of immigration toward cities among the families with mid- to high-income, which explains the very low population rate increase: a total of 242 in 1997, 260 in 2007 and 292 in 2017 [9].

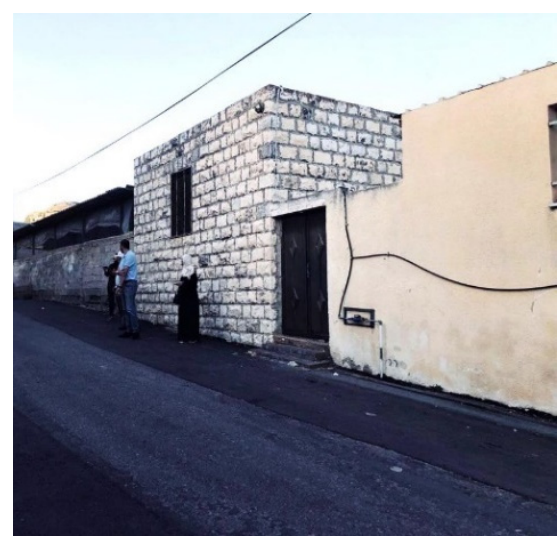

(a)

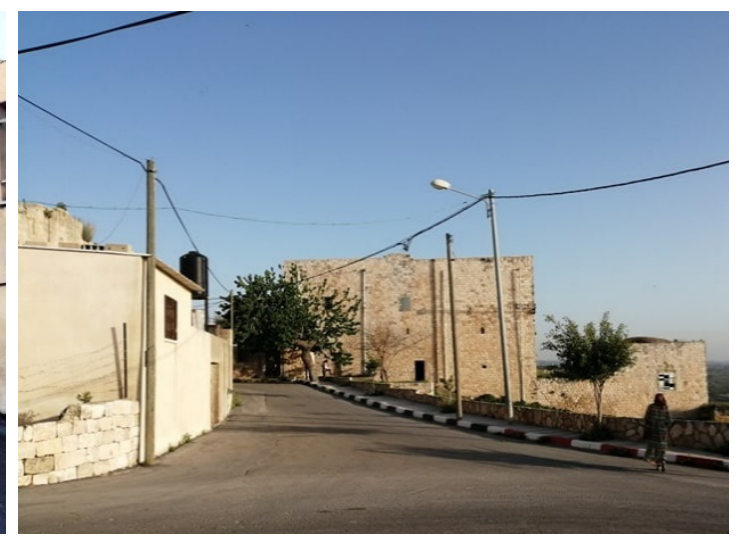

(b)

Figure 10: Plastered concrete block additions to buildings, Kour. (Source: Researcher, 2019.)

\subsection{Improper restorations}

Old buildings restoration and rehabilitation processes must be carried out and supervised by professionals. Investigations and treatment processes should be preceded by tests and experiments to confirm the validity of the restorations, otherwise it will lead to inappropriate interventions, as mentioned previously [7].

\section{CASE STUDIES}

\subsection{Al Barqawi castle}

Located in Shoufa village, $8 \mathrm{~km}$ to the southeast of Tulkarm [10], Al Barquawi castle is considered an outstanding example of Throne village architecture. Also known as "Dar Al Sheikh", this castle goes back over 350 years, owned by the Barqawi family which has been living there since the Ottoman rule in the 18th century [2]. Al Barqawi castle, located on the highest point of Shoufa village, stands as a symbol of heritage and authenticity of history, and highlights the cultural life and national heritage of the people of Palestine in general, and Tulkarm in particular [11]. According to one of the Barqawi family public figures, Ahmad Barqawi, the castle was also named after Shoufa village, as "Shoufa castle", which means the castle with a view, as it is located $360 \mathrm{~m}$ above sea level, $20 \mathrm{~km}$ away from the Mediterranean Sea [12]. 
The castle included the governor's residence/palace, and an Ottoman mosque and a historical monument. The castle is considered a tourists destination. As other Throne village castles, it consists of a central inner courtyard, surrounded mainly by two floors (Fig. 11(a)). The castle's building consists of a number of stacked masses to serve a defensive and protection concept on the one hand; and on the other hand, to provide needed privacy for the governor's family (Fig. 11(b)) [13].

The exterior façades of the castle were designed with small openings and the exterior façades were decorated with pointed arches that contained the main entrances and entrances to the lower floor, as shown in Fig. 12.

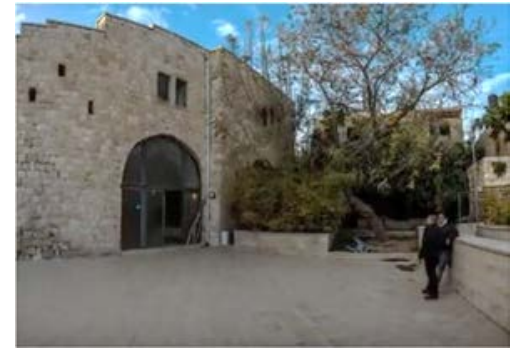

(a)

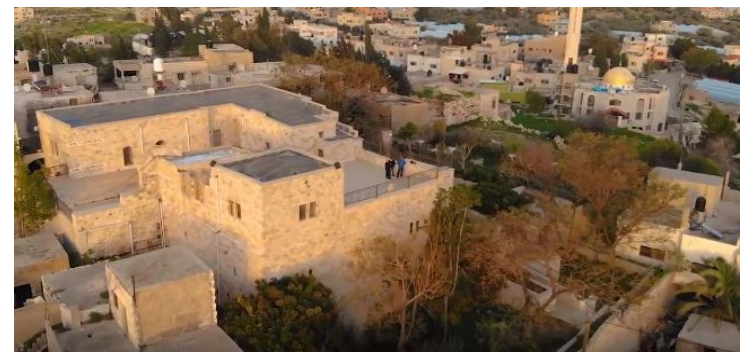

(b)

Figure 11: (a) Inner courtyard, Al Barqawi castle; (b) Al Barqawi castle building. (Source: Al Barqawi castle, 2019.)

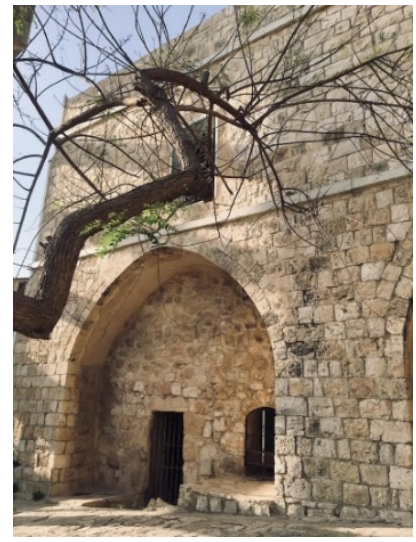

(a)

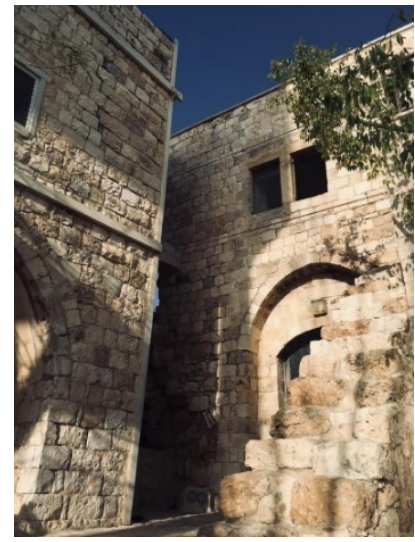

(b)

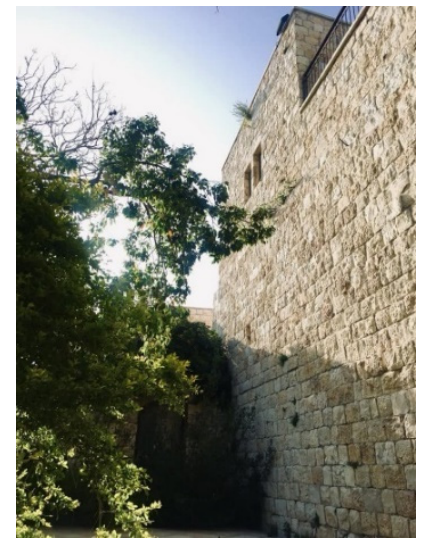

(c)

Figure 12: Al Barqawi castle. (a) Pointed arches, basements entrances; (b) The castle's building masses and main entrance; and (c) Solid outer walls. (Source: Researcher, 2019.)

Field visits and observations in Al Barqawi castle set some evaluation points to restoration processes. The restoration of such an important inherited architectural site is an achievement itself toward the preservation of culture and identity; however, despite efforts by the Ministry of Culture, this castle suffered from poverty among some fundamental points, summarised as follows: 
- The policy of postponing the use of the building by its occupants for a predetermined period after restoration weakens the optimal exploitation of such buildings; and thus, weakens economic sustainability in terms of the establishment of events to achieve the necessary financial revenues for the castle. Moreover, there are poor interest in tourism and poor application of recreational events or cultural activities in the castle.

- Shallow solutions to some of the major problems in the restoration process, for example the problem of moisture, which was covered only by using paint, which recreated the problem in a very short time.

- The village lacks innovative and interactive projects that encourage visitors, tourists and Palestinian citizens to visit the village of Shoufa and Al Barqawi castle.

- Incomplete restorations faced failure and an absence of maintenance.

- Al-Barqawi castle suffered from lack of an operational plan, with recommendations and strategies for its revival, to emphasise its historical and cultural role.

\subsection{Al Jayyousi palace}

This palace, also known as "Waked Palace", was built in 1842 is located $19 \mathrm{~km}$ to the south of Tulkarm, in the village of Kour. The palace was named after Sheik Yousef Waked Al Jayyousi, who ruled the village of Kour back in the 1920s and was known for his generosity, according to the poetry carved at the entrance of the palace [2]. The palace was restored partially in 2003 and 2006, through United Nations (UN) restoration projects in Palestine [14]. The palace consists of connected buildings opens to a central courtyard; the palace has more than 30 rooms distributed on two floors; the ground floor included rooms for food preparation, storage and stables. There are remains of stone walls in the courtyard; connected with the upper floors using a stone staircase, which included guests rooms, living rooms, bedrooms and their services; with a connecting corridor that opens toward the courtyard, as shown in the ground floor plan and section A-A, seen in Fig. 13, top and bottom, respectively [3].
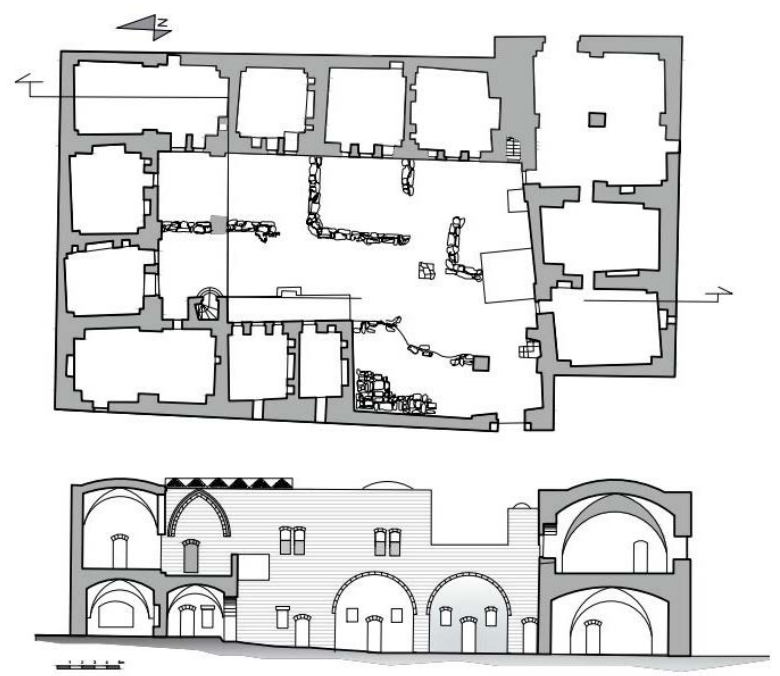

Figure 13: Top: Ground floor plan; Bottom: Section A-A north-south section. (Source: The Researcher based on Riwaq, 2019.) 
Al Jayyousi palace's design was based on the architectural form of Throne villages architecture; the defensive architectural features of high walls and small external openings are directly noticeable. Crossed vaults were used for ceilings, except for the governor's room, which had a dome ceiling; pointed arches were used at the entrance and the arcades surrounding the courtyard (Fig. 14(a)). Al Jayyousi palace has a large, monumental main entrance (Fig. 14(b)).

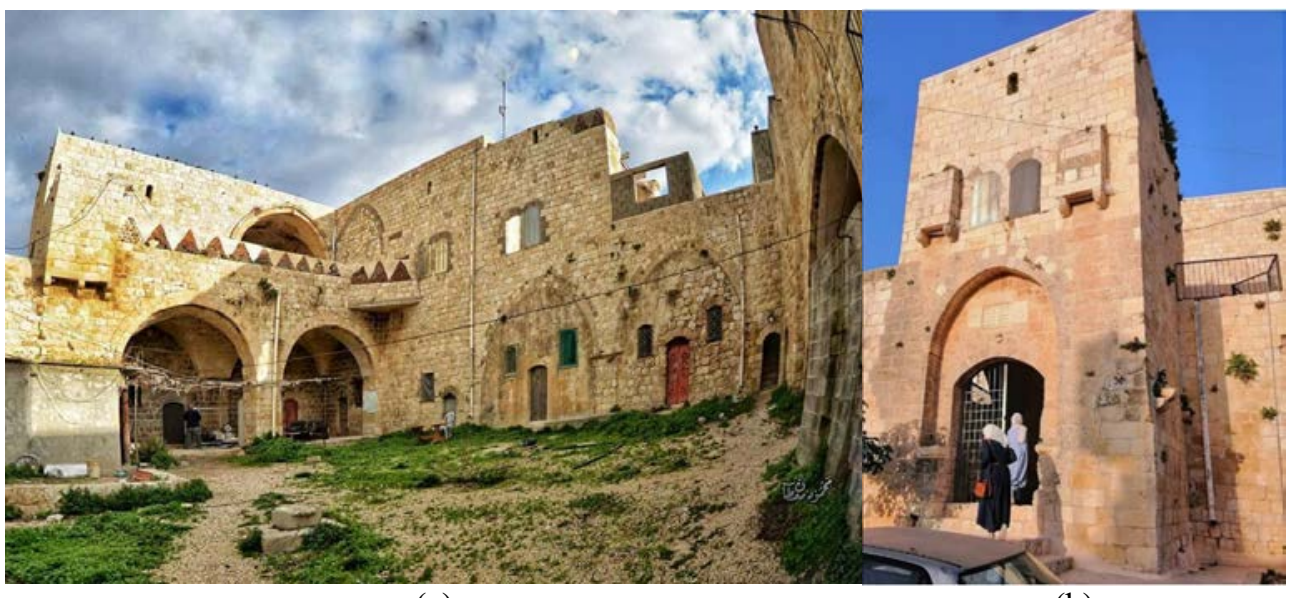

(a)

(b)

Figure 14: Al Jayyousi palace. (a) Courtyard; and (b) Entrance. (Source: Researcher, 2019.)

The restoration efforts and rehabilitation in the Throne villages were part of the "50 villages restoration project", accomplished by the Riwaq Institution for Architectural Heritage Revival and Restoration since 2007. Among these, Al Jayyousi palace was one of the four main palaces restored in Kour [15]. This paper overviews some evaluation points for the reuse and rehabilitation process so far, based on observation and site visits, summarized as follows:

- Al Jayyousi palace suffers from the lack of continuous maintenance services and cleaning of harmful plants growing in its courtyard; which reflects carelessness and lack of responsibility in its residents, whom are not from the palace's original owners and residents.

- Unsustainable and irresponsible interventions like additions using concrete block.

- The application of shallow solutions for problems like moisture and dampness.

- Interventions had extended the building form to affect its functionality; for example, the intolerance of the courtyard function, due to partial closing of the surrounding arcades or parts of the roof, which play an important role in enhancing air circulation in the courtyard; therefore playing a significant role in the building's thermal and visual comfort.

\section{DISCUSSION}

This paper introduces a conceptual design example for restoring and reusing Al Jayyousi palace as a tourists motel in the historical village of Kour. Al Jayyousi palace, as well other Throne villages palaces and castles, could be rehabilitated as a tourists motel because of its 
spacious courtyard and large number of rooms. The proposed designs concept emphasizes the importance of the central courtyard for cultural and social interaction activities.

The project includes the palace's two floors: the ground floor which starts with the palace's main entrance; the spacious reception hall with its cross-vaulted ceiling that welcomes the guests, which directly opens toward the courtyard that includes exterior dining areas. Other rooms could be used as administrative offices and for other needed services. The palace's different room sizes provide needed flexibility in the numbers of beds in each room, as is shown in the ground floor design in Fig. 15(a). The first floor can be rehabilitated to include visitors rooms, with its needed services distributed around the courtyard in the palace's original rooms, as shown in section B-B (Fig. 15(b)). The ground and first floors are vertically connected using the original stone staircases. The porch on the first floor could also be used as a terrace for events.

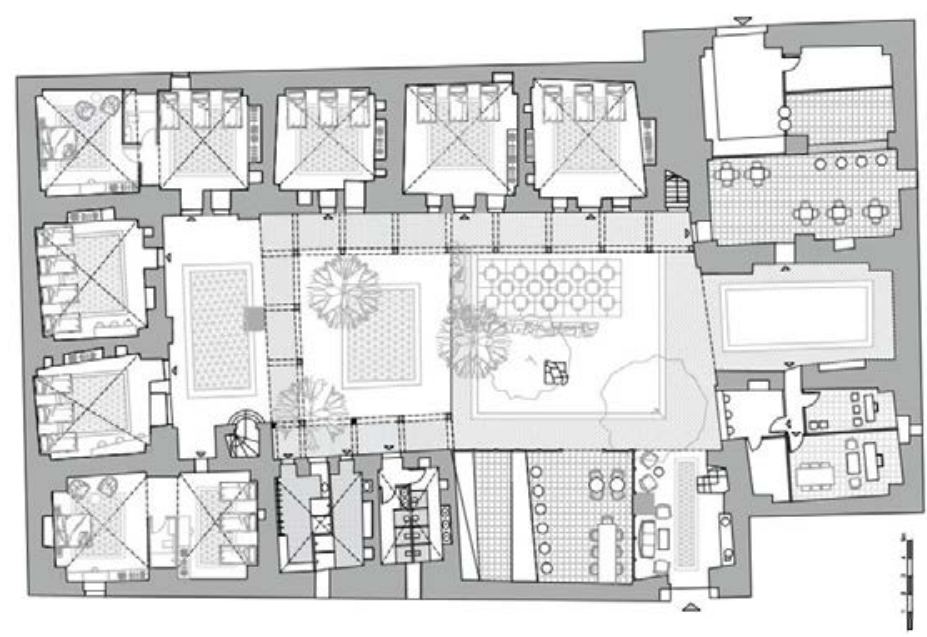

(a)

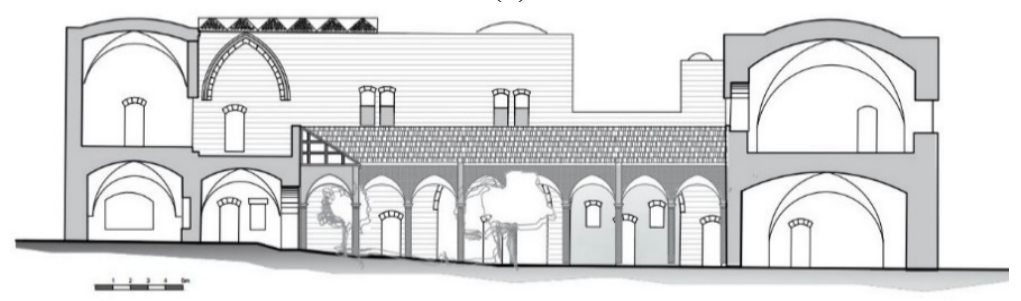

(b)

Figure 15: Al Jayyousi palace. (a) Ground floor plan; and (b) Section B-B. (Source: Researcher, 2019.)

\section{CONCLUSION AND RECOMMENDATIONS}

This paper focuses on the importance of Palestinian architectural heritage and its contribution to the Palestinian identity. It illustrates examples of the architecture of Throne villages in Palestine, highlighting two of the most distinctive architectural sites, Al Barqawi castle and Al Jayyousi palace, examples of such inherited treasures. Reuse of these buildings as 
interacting profitable projects will help elongate their life cycle, by increasing the number of visitors and therefore, cover maintenance expenses.

A critical evaluating analysis about the restoration projects reviews what has been accomplished in each site. Our paper aims to introduce future recommendations to increase awareness and an understanding of the importance of such inherited architectural treasures.

The recommended reuse and revival strategies are summarised as follows:

- Encourage the Ministry of Tourism and the municipality of Tulkarm to include the villages of Shoufa and Kour as part of the tourist sightseeing route program; which assures a larger number of visitors.

- Introduce essential and additional caring of tourism, to encourage visitors to learn more about Throne villages.

- Develop a strategic plan to reuse the castles and palaces for cultural and social events, conferences and workshop destinations; to introduce creative revival solutions to reuse these palaces and castles as tourist hotels, cultural centres, galleries or museums.

- Use outdoor squares, plazas and roofs for local festivals and events, or as dining restaurants and cafés, to enhance their role as tourist attractions on the one hand, and provide financial returns as a part of the sites economic sustainability.

- Finally, this paper confirms the importance of having legal power to influence the local authorities to prohibit either partial or complete demolishing of such old and historical buildings. Moreover, this paper encourages continued updating of registered historical buildings records; and also, to encourage inspirational design concepts for revival projects, through creative architectural competitions.

\section{REFERENCES}

[1] Aqel, M., Phrases in The Geography of Palestine, Donia Al Watan, 23 Oct. 2013.

[2] Amiri, S., Throne Villages and Countryside Families in Palestine, yaf.ps: Ramallah, pp. 10-35, 2017.

[3] R.-C. f. A., Conservation and Suad Amiri, Throne Villages: The History of Rural Village of Palestine in the 18th-19th Centuries, Riwaq: Ramallah, 2003.

[4] Moqady, O., Revival of the Historical Center of Throne Villages: Deir Estya as a Case Study, Al Najah National University: Nablus, 2008.

[5] Abdulqader, H. \& Al Jayyousi, M., Urban Reservation and Rehabilitation, Beir Zeit University: Ramallah, 2010.

[6] Amiry, S., Peasant Architecture in Palestine, Riwaq: Ramallah, 2018.

[7] Mahari, S.A., Historical Buildings Preservation.

[8] Raya News Network, Kour Village, Tulkarm, 2016.

[9] Palestinian Central Bureau of Statistics, Ramallah, 2017.

[10] Palestine Blog, Shoufa Village, Tulkarm, p. 1, 25 Jan. 2017.

[11] Al Barqawi Castle: A unique castle in Tulkarm (Film), Tulkarm: Palestine Heaven on Earth.

[12] Palestine Blog, 11 Oct. 2017. https:/mohammadhamdan64.wordpress.com/2017/10/ 11/ قرية_شوفة_منطقة_طولكرم/[Shoufa village, Tulkarem]. Accessed on: 1 Apr. 2019.

[13] Najjar, B., Al Barqawi Castle, Donia al Watan, 22 Feb. 2016.

[14] Raya News Network, Kour Village, Ramallah, 2016.

[15] Have you heard of Kour village? 28 Aug. 2017. http://asdaapress.com/?ID=26338. Accessed on: 2 Apr. 2019. 